Álvaro Rocha - Carlos Ferrás

Manolo Paredes

Editors

\title{
Information Technology and Systems
}

Proceedings of ICITS 2019

算 Springer 
Editors

Álvaro Rocha

DEI/FCT

Universidade de Coimbra

Coimbra, Portugal

Manolo Paredes

Departamento de Eléctrica, Electrónica y

Telecomunicaciones

Universidad de las Fuerzas Armadas

"ESPE"

Sangolqui, Ecuador
Carlos Ferrás

Facultad de Geografía

Universidad de Santiago de Compostela

Santiago Compostela, La Coruña, Spain

ISSN 2194-5357

ISSN 2194-5365 (electronic)

Advances in Intelligent Systems and Computing

ISBN 978-3-030-11889-1

ISBN 978-3-030-11890-7 (eBook)

https://doi.org/10.1007/978-3-030-11890-7

Library of Congress Control Number: 2018967946

(C) Springer Nature Switzerland AG 2019, corrected publication 2020

This work is subject to copyright. All rights are reserved by the Publisher, whether the whole or part of the material is concerned, specifically the rights of translation, reprinting, reuse of illustrations, recitation, broadcasting, reproduction on microfilms or in any other physical way, and transmission or information storage and retrieval, electronic adaptation, computer software, or by similar or dissimilar methodology now known or hereafter developed.

The use of general descriptive names, registered names, trademarks, service marks, etc. in this publication does not imply, even in the absence of a specific statement, that such names are exempt from the relevant protective laws and regulations and therefore free for general use.

The publisher, the authors and the editors are safe to assume that the advice and information in this book are believed to be true and accurate at the date of publication. Neither the publisher nor the authors or the editors give a warranty, express or implied, with respect to the material contained herein or for any errors or omissions that may have been made. The publisher remains neutral with regard to jurisdictional claims in published maps and institutional affiliations.

This Springer imprint is published by the registered company Springer Nature Switzerland AG

The registered company address is: Gewerbestrasse 11, 6330 Cham, Switzerland 


\section{Preface}

This book is composed by the papers written in English and accepted for presentation and discussion at The 2019 International Conference on Information Technology \& Systems (ICITS'19). This conference had the support of the University of Armed Forces (Universidad de las Fuerzas Armadas "ESPE"), IEEE Systems, Man, and Cybernetics Society, and AISTI (Iberian Association for Information Systems and Technologies). It took place at Sangolquí, Quito, Ecuador, February 6-8, 2019.

The 2019 International Conference on Information Technology \& Systems (ICITS'19) is an international forum for researchers and practitioners to present and discuss the most recent innovations, trends, results, experiences, and concerns in the several perspectives of information technology and systems.

The Program Committee of ICITS'19 was composed of a multidisciplinary group of 152 experts and those who are intimately concerned with information systems and technologies. They have had the responsibility for evaluating, in a 'double-blind review' process, the papers received for each of the main themes proposed for the conference: (A) Information and Knowledge Management; (B) Organizational Models and Information Systems; (C) Software and Systems Modeling; (D) Software Systems, Architectures, Applications and Tools; (E) Multimedia Systems and Applications; (F) Computer Networks, Mobility, and Pervasive Systems; (G) Intelligent and Decision Support Systems; (H) Big Data Analytics and Applications; (I) Human-Computer Interaction; (J) Ethics, Computers and Security; (K) Health Informatics; (L) Information Technologies in Education; (M) Cybersecurity and Cyber-defense; (N) Electromagnetics, Sensors and Antennas for Security.

ICITS'19 also included several workshop sessions taking place in parallel with the conference ones. They were sessions of the WMETACOM 2019 - 2nd Workshop on Media, Applied Technology and Communication.

ICITS' 19 received about 300 contributions from 31 countries around the world. The papers accepted for presentation and discussion at the conference are published by Springer (this book) and by AISTI, and will be submitted for indexing by ISI, EI-Compendex, SCOPUS, DBLP and/or Google Scholar, among others. 
We acknowledge all of those that contributed to the staging of ICITS'19 (authors, committees, workshop organizers and sponsors). We deeply appreciate their involvement and support that was crucial for the success of ICITS' 19.

February 2019

Álvaro Rocha

Carlos Ferrás

Manolo Paredes 


\section{Organization}

\section{Conference}

\section{Honorary Chair}

Álvaro Rocha University of Coimbra, Portugal

\section{Scientific Committee Chair}

Carlos Ferrás Sexto University of Santiago de Compostela, Spain

\section{Local Organizing Chair}

Manolo Paredes Universidad de las Fuerzas Armadas "ESPE", Ecuador

\section{Local Organizing Committee}

Hugo Perez

Patricio Reyes

Gonzalo Olmedo
Universidad de las Fuerzas Armadas "ESPE", Ecuador

Universidad de las Fuerzas Armadas "ESPE", Ecuador

Universidad de las Fuerzas Armadas "ESPE", Ecuador 


\section{Scientific Committee}

Abdulmotaleb El Saddik

Alexandra González

Alexandru Vulpe

Amal Al Ali

Ana V. Guamán

André da Silva

André Marcos Silva

André Kawamoto

Angeles Quezada

Ania Cravero

Ankur Bist

António Augusto Gonçalves

Antonio Raffo

Anushia Inthiran

Ari Mariano

Benardine Onah

Borja Bordel

Carlos Cares

Carlos Carreto

Carlos Grilo

Carlos Hernan Fajardo Toro

Dalila Durães

Dália Filipa Liberato

Daniela Benalcázar

Dante Carrizo

Diego Marcillo

Diego Ordóñez-Camacho

Eddie Galarza

Edgar Serna

Edison Loza-Aguirre

Efraín R. Fonseca C.

Egils Ginters

Enrique Carrera

Ewaryst Tkacz

Fabio Gomes Rocha
University of Ottawa, Canada

Universidad Tecnica Particular de Loja, Ecuador

University Politehnica of Bucharest, Romania

University of Sharjah, United Arab Emirates

Universidad de las Fuerzas Armadas "ESPE",

Ecuador

IFSP and NIED/UNICAMP, Brazil

University Adventist of São Paulo, Brazil

Federal University of Technology, Brazil

Universidad Autonoma de Baja California, Mexico

University de La Frontera, Chile

KIET Ghaziabad, India

Universidade Estacio de Sá, Brazil

University of Calabria, Italy

University of Canterbury, New Zealand

Universidade de Brasília, Brazil

University of Nigeria, Nigeria

Universidad Politécnica de Madrid, Spain

Universidad de La Frontera, Chile

Polytechnic of Guarda, Portugal

Polytechnic of Leiria, Portugal

Universidad EAN, Colombia

Technical University of Madrid, Spain

ESHT/IPP, Portugal

Universidad Técnica de Ambato, Ecuador

Universidad de Atacama, Chile

Universidad de las Fuerzas Armadas "ESPE", Ecuador

Universidad Tecnológica Equinoccial, Ecuador

Universidad de las Fuerzas Armadas "ESPE",

Ecuador

Universidad Autónoma Latinoamericana, Colombia

Escuela Politécnica Nacional, Ecuador

Universidad de las Fuerzas Armadas "ESPE",

Ecuador

Riga Technical University, Latvia

Universidad de las Fuerzas Armadas "ESPE",

Ecuador

Silesian University of Technology, Poland

Tiradentes University, Brazil 
Felix Blazquez Lozano

Filipa Ferraz

Filipe Sá

Felipe Machorro-Ramos

Francesc Gine

Francisco Valverde

Franklim Silva

Frederico Branco

Gabriel Elías Chanchí Golondrino

Gabriel Pestana

George Suciu

Gladys Alicia Tenesaca Luna

Hector Florez

Henrique Lopes Cardoso

Ildeberto Rodello

Isabel Pedrosa

Jan Kubicek

Javier Criado

João Paulo Pereira

João Vidal de Carvalho

Jorge Buele

Jorge Herrera-Tapia

Jorge Luis Pérez

Jose Aguilar

José Álvarez-García

José Araújo

José Luís Silva

Juan Jesus Ojeda

Juan M. Ferreira

Júlio Menezes Jr.

Jussi Okkonen

Justyna Trojanowska

Korhan Gunel

Leandro Flórez Aristizábal

Leonardo Botega

Lorena Siguenza-Guzman

Mafalda Teles Roxo

Manuel Au-Yong-Oliveira
University of A Coruña, Spain

University of Minho, Portugal

Câmara Municipal de Penacova, Portugal

Universidad de las Américas Puebla, Mexico

University of Lleida, Spain

Universidad Central del Ecuador, Ecuador

Universidad de las Fuerzas Armadas "ESPE", Ecuador

Universidade de Trás-os-Montes e Alto Douro, Portugal

Institución Universitaria Colegio Mayor del

Cauca, Colombia

Universidade Europeia, Portugal

BEIA, Romania

Universidad Técnica Particular de Loja, Ecuador

Universidad Distrital Francisco Jose de Caldas, Colombia

University of Porto, Portugal

University of São Paulo, Brazil

Coimbra Business School - ISCAC, Portugal

Faculty of Electrical Engineering and Computer

Science VŠB-TUO, Czech Republic

University of Almería, Spain

Polytechnic of Bragança, Portugal

ISCAP/IPP, Portugal

Universidad Técnica de Ambato, Ecuador

Universidad Laica Eloy Alfaro de Manabí,

Ecuador

Universidad de Las Américas, Ecuador

Universidad de Los Andes, Venezuela

University of Extremadura, Spain

SAP, Portugal

ISCTE-IUL and Madeira-ITI, Portugal

University of Almeria, Spain

Senate, Paraguay

Federal University of Pernambuco, Brazil

University of Tampere, Finland

Poznan University of Technology, Poland

Adnan Menderes University, Turkey

Antonio Jose Camacho University Institute,

Colombia

UNIVEM, Brazil

Universidad de Cuenca, Ecuador

INESC TEC, Portugal

University of Aveiro, Portugal 
Manuel Monteiro

Marciele Berger

Marco Quintana

Maria Amelia Eliseo

María de la Cruz del Río-Rama

Maria de las Mercedes Canavesio

María Dolores Sánchez

Fernández

Maria José Sousa

Maria Koziri

María Teresa García-Álvarez

Marisela Giraldo de Lopez

Maristela Holanda

Mohamed Abouzeid

Monica Leba

Nadjet Kamel

Nelson Piedra

Nelson Rocha

Nikolai Prokopyev

Nikolaos Giannakeas

Niranjan S. K.

Nomusa Dlodlo

Olmer Garcia

Patricia Acosta

Pablo Alejandro Quezada

Sarmiento

Patricia Alexandra Quiroz Palma

Patricia Henriquez-Coronel

Paulus Isap Santosa

Pedro Fernandes de Oliveira Gomes

Pedro Liberato

Piotr Kulczycki

Ramayah T.

Ramon Alcarria

Roberto Santana
Hospital Particular São Lucas, Portugal

University of Minho, Portugal

UIDE, Ecuador

Universidade Presbiteriana Mackenzie, Brazil

University of Vigo, Spain

UTN - Facultad Regional Santa Fe, Argentina

University of Coruña, Spain

University of Coimbra, Portugal

University of Thessaly, Greece

University of A Coruna, Spain

Universidad Técnica del Norte, Ecuador

University of Brasilia, Brazil

Innovations for High Performance

Microelectronics IHP, Germany

University of Petrosani, Romania

University Ferhat Abbas Setif 1, Algeria

Universidad Técnica Particular de Loja, Ecuador

University of Aveiro, Portugal

Russian Academy of Sciences, Russia

Technology Educational Institute of Epirus,

Greece

JSS Science and Technology University, India

Namibia University of Science and Technology,

South Africa

Universidad de Bogota Jorge Tadeo Lozano,

Colombia

Universidad de Las Américas, Ecuador

Universidad Internacional del Ecuador, Ecuador

Universidad Politécnica de Valencia, Spain

ULEAM, Ecuador

Gadjah Mada University, Indonesia

State University of Maringá, Brazil

ESHT/IPP, Portugal

Systems Research Institute, Polish Academy

of Sciences, Poland

Universiti Sains Malaysia, Malaysia

Universidad Politécnica de Madrid, Spain

University of the Basque Country (UPV/EHU), Spain 
Robson Lemos

Ramiro Delgado

Prabhat Mahanti

Saide

Samanta Patricia Cueva Carrión

Sampsa Rauti

Sanaz Kavianpour

Sandra Costanzo

Santoso Wibowo

Saulo Barbará Oliveira

Sergio Luján-Mora

Sylvie Ratté

Teresa Guarda

Thanasis Loukopoulos

Theofilos Toulkeridis

Valeria Farinazzo Martins

Vania Ribas Ulbricht

Victor Georgiev

Villie Morocho

Vitor Santos

Ville Leppänen

Vladislav Gorbunov

Wilmar Hernandez

Wilmar Yesid Campo Muñoz

Willian Zamora
Federal University of Santa Catarina, Brazil

Universidad de las Fuerzas Armadas "ESPE", Ecuador

University of New Brunswick, Canada

Information System (PRO-Knowledge Group), Indonesia

Universidad Técnica Particular de Loja, Ecuador

University of Turku, Finland

University of Technology, Malaysia

University of Calabria, Italy

CQUniversity, Australia

Universidade Federal Rural do Rio de Janeiro, Brazil

University of Alicante, Spain

École de Technologie Supérieure, Canada

State University of Santa Elena Peninsula, Ecuador

University of Thessaly, Greece

Universidad de las Fuerzas Armadas "ESPE",

Ecuador

Presbyterian University Mackenzie, Brazil

Universidade Federal de Santa Catarina, Brazil

Russian Academy of Sciences, Russia

Universidad de Cuenca, Ecuador

Universidade Nova de Lisboa, Portugal

University of Turku, Finland

Russian Academy of Sciences, Russia

Universidad de Las Americas, Ecuador

Universidad del Quindío, Colombia

Universidad Politécnica de Valencia, Spain 


\section{Contents}

Information and Knowledge Management

Management of Natural Disasters Based on Twitter Analytics.

2017 Mexico Earthquake . . . . . . . . . . . . . . . . . . 3

Patricia Henríquez-Coronel, Julio García García, and Jorge Herrera-Tapia

E-Government and the Quality of Information in Web Portals

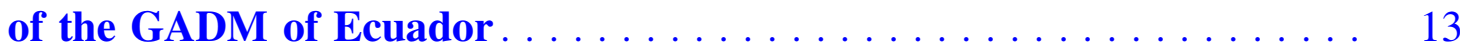

Patricia Henríquez-Coronel, Jennifer Bravo-Loor, Enrique Díaz-Barrera,

and Yosselin Vélez-Romero

The Contribution of Knowledge Engineering in Supply Chain:

A Literature Review . . . . . . . . . . . . . . . . . . . . . . 21

Fatima Ezzahra Ettahiri and Mina Elmaallam

The Destination Choice by Generation $Z$ Influenced

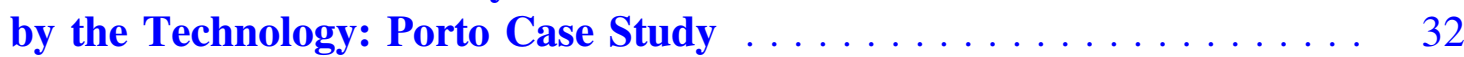

Pedro Liberato, Cátia Aires, Dália Liberato, and Álvaro Rocha

A Data Mining Approach for Predicting Academic Success -

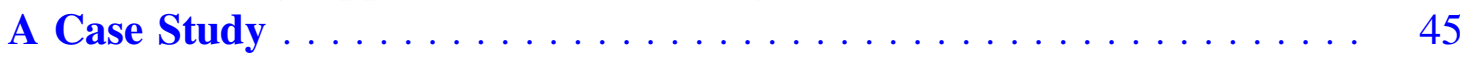

Maria P. G. Martins, Vera L. Miguéis, D. S. B. Fonseca, and Albano Alves

Data Analytics on Real-Time Air Pollution Monitoring System

Derived from a Wireless Sensor Network. . . . . . . . . . . . . 57

Walter Fuertes, Alyssa Cadena, Jenny Torres, Diego Benítez,

Freddy Tapia, and Theofilos Toulkeridis

Analyzing Scientific Corpora Using Word Embedding . . . . . . . . . 68

Veronica Segarra-Faggioni and Audrey Romero-Pelaez 


\title{
A Data Mining Approach for Predicting Academic Success - A Case Study
}

\author{
Maria P. G. Martins ${ }^{1,3(\bowtie)}$, Vera L. Miguéis ${ }^{2}$, D. S. B. Fonseca ${ }^{3}$, \\ and Albano Alves ${ }^{1}$ \\ 1 School of Technology and Management, Polytechnic Institute of Bragança, \\ Campus de Santa Apolónia, 5300-253 Bragança, Portugal \\ prud@ipb.pt \\ 2 Faculty of Engineering, University of Porto, \\ Rua Dr. Roberto Frias, 4200-465 Porto, Portugal \\ 3 CISE - Electromechatronic Systems Research Centre, University of Beira Interior, \\ Calçada Fonte do Lameiro, P, 6201-001 Covilhã, Portugal
}

\begin{abstract}
The present study puts forward a regression analytic model based on the random forest algorithm, developed to predict, at an early stage, the global academic performance of the undergraduates of a polytechnic higher education institution. The study targets the universe of an institution composed of 5 schools rather than following the usual procedure of delimiting the prediction to one single specific degree course. Hence, we intend to provide the institution with one single tool capable of including the heterogeneity of the universe of students as well as educational dynamics. A different approach to feature selection is proposed, which enables to completely exclude categories of predictive variables, making the model useful for scenarios in which not all categories of data considered are collected. The introduced model can be used at a central level by the decision-makers who are entitled to design actions to mitigate academic failure.
\end{abstract}

Keywords: Data mining - Educational data mining - Prediction • Academic success $\cdot$ Random forest $\cdot$ Regression

\section{Introduction}

The quality of academic training has a paramount role in the growth and development of any country or society. In turn, educational success is closely linked to the efficacy and efficiency of educational institutions. For this reason, the delivery of high-quality training and the definition of strategies which may promote academic success as well as retention recovery have been the subject of deep reflection by the administration board of the Polytechnic Institute of Bragança (IPB - Instituto Politécnico de Bragança), a polytechnic higher education institution in inland Portugal. Therefore, the aim to provide a methodology which enables the obtainment of useful knowledge to help and ground decision-making 
by the IPB management bodies created the need to develop an academic success predictive model, which fits educational data mining field.

This work presents a regression model based on the random forest algorithm [1], developed with the aim to predict at an early stage the global academic performance of IPB undergraduates at the terminus of their academic path.

After this introduction, the present paper is composed of the following sections: Sect. 2 - outline of related studies; Sect. 3 - presentation of the methodology and of the data model developed; Sect. 4 - presentation of results and of the prediction model of performance proposed; Sect. 5 - final discussion of results and respective conclusions.

\section{Related Studies}

The main goal of educational data mining (EDM) is to generate useful knowledge which may ground and sustain decision-making targeted at improving student communities' learning as well as educational institutions' efficiency. Several systematic literature reviews [2-9] give evidence of the growing importance of EDM throughout time and refer and analyse the main research topics in which EDM has shown a remarkable contribution as a management analysis and support tool. Also, such studies provide evidence of the usefulness, potential and efficacy of the most used data mining methods and algorithms.

Among the typology of tasks where EDM has shown a remarkable contribution, we can find the prediction of academic performance. This research topic is normally approached from three different perspectives: predicting school dropout, predicting retention, or predicting academic success at the end of the degree course. Literature on EDM has shown that within those studies, several authors over time have studied a number of factors which promote academic success or failure. The main goal of the studies $[10,11]$ was to conduct a review on the most used and relevant factors for this kind of predictions. Simultaneously, the authors also intended to determine the main data mining methods and algorithms used in such studies. After analysing a set of 30 studies focusing on the topic, Shahiri et al. [10] conclude that 6 attributes are used most frequently. At the top of the list is the cumulative grade points average (CGPA), almost at the same level as the attributes of internal assessment (marks after entering higher education such as assignments, exams, attendance, etc.). Demographic features and external assessment (pre-university achievement classifications) were the second group of most used attributes. Finally, the third group of attributes that the authors considered to be most used among the set of 6 are the ones related to students' extra-curricular activities and social interaction.

In a similar study to that by Shahiri et al. [10], but with the particularity of focusing only on research related to students attending institutions of the traditional on-site system, Del Río and Insuasti [11] conclude that in order to infer the final mean of the degree course, the authors of a set of 51 studies released between 2011 and August 2016 used, as predictive variables, indicators of academic performance obtained after entering higher education in combination with another type of attribute in $51.8 \%$ of the studies. In $37.5 \%$ of the 
papers, they only used information on academic performance within higher education. Among the data mining methods most used in the EDM task, the same authors [11] highlight those regarding classification, reported in $71.4 \%$ of the research works mentioned. The methods which followed were those of clustering and association rules, present in $8.9 \%$ and $7.1 \%$ of the studies.

Regarding the predicting academic success at the end of the degree course, the majority of the works related analyse academic performance restricted to one degree course only, and use relatively small datasets. For example, Natek and Zwilling [12] concluded that the factors most visibly influencing the final mean of the undergraduates of the bachelor degree in Computer Science were connected to information regarding access, demography and extra-curricular activities. The data were processed by the classification algorithms RepTree Model, J48 Model and M5P Model, and concerned 42 students attending the 1st year of the degree course, 32 attending the 2 nd year, and 32 attending the $3 \mathrm{rd}$ year.

The results of the study conducted by Asif, Merceron, Ali and Haider [13] show that through algorithms Naïve Bayes and random forest Trees, it is possible to predict, with a high level of precision, the global graduation performance of a four-year degree course, by using only pre-university marks and the marks obtained in the course units of the 1st and 2nd years of university.

In the study by Migueis et al. [14], random forest, decision trees, support vector machines, Naïve Bayes, bagged trees and boosted trees were used to predict overall students academic performance based on the information available at the end of the first academic year. Among the algorithms used, random forest was the one that showed the best predictive results, also providing evidence that the most important factors to predict and explain the level of academic success in five-year degree courses in Engineering are the means regarding university access and university access examinations, as well as the mean obtained in the course units of the first academic year. This study also proposes a multiclass segmentation structure, aiming an early classification of students, based on their performance observed at the end of the first academic year and on their propensity for academic success revealed by the predictive model.

\section{Methodology and Data Model}

For the creation of a predictive model which can predict students' academic success at the terminus of their academic path, we chose to explore data from a universe of students from different educational fields, attending about half a hundred degree courses in an institution made up of 5 schools instead of following the most common procedure of delimiting the prediction to one single specific course. Hence, we intend to provide the institution with one single tool capable of including the heterogeneity of the universe of students as well as educational dynamics. The aim is for this tool to be used at a central level by the decisionmakers who are entitled to design actions to mitigate academic failure, thus promoting a better educational experience for their students. 
In this study, we chose to base our predictive model on the random forest algorithm proposed by Breiman [1]. It has shown to have surpassed other techniques in similar studies due to its predictive capacity and, more importantly, it allows a good interpretation of its results, in contrast to other techniques, such as Neural Networks and Support Vector Machines, which are considered to be black boxes. In fact, random forest presents the interesting functionality of allowing ordering the importance of the predictors which sustain the model.

Following the procedure commonly adopted, the predictive performance of the models considered was evaluated using a $k$-fold (with $k=10$ ) crossvalidation. As for the model evaluation metrics, the determination coefficient $\left(R^{2}\right)$ and the root mean squared error (RMSE) were used.

In order to determine students' academic performance, the dependent variable introduced in expression (1) was used as a success indicator,

$$
d v=\text { average } \times \frac{\text { ects_aprov }}{\text { ects_aprov }+ \text { ects_disaprov }},
$$

where average is the weighted average of the marks obtained in the completed course units (CUs), ects_aprov is the number of ECTS completed successfully and ects_disaprov is the number of ECTS in which students enrolled but did not pass. Thus, the metric takes into account not only the students' classification average but also the fraction of matriculations in course units they passed (ratio of successful 'attempts').

It was possible to consider the time period comprised between 2007/2008 and 2015/2016, totalising 9 consecutive academic years. A choice was made to limit the study to the bachelor degree courses since they are the core of the institution's training offer and they encompass a more complete set of data. After a cleaning of data and other pre-processing tasks, the data set that this study focuses on comprised 4530 matriculations in bachelor degree courses concluded in the period between $2007 / 2008$ and $2015 / 2016$ and started in the period between $2007 / 2008$ and $2013 / 2014$.

Regarding the predictive variables of academic success, we considered essentially the same typology of variables used in the related works of reference, namely academic data of sociodemographic nature and of access to higher education. The variables under study can be classified in two important subgroups: variables with cumulative semestral curricular results and 'timeless' variables variables whose values are unaltered throughout students' academic path. Table 1 presents all the 44 predictive variables considered in this study as well as the dependent variable $\mathrm{dv}$ which will be used as a success indicator according to Eq. (1).

A vast real data set was used in this study, so care was taken to classify (3rd column of the table) each one of the potential predictive variables of academic success according to their nature into five different categories: curricular (C), matriculation (M), demographic (D), socioeconomic (S) and access (A). The attributes regarding semestral data (all in category $\mathrm{C}$ ) are also easily distinguished from the others (timeless data) through the suffix '_s'. Note that the 
Table 1. List of variables sustaining the model.

\begin{tabular}{|c|c|c|c|c|c|}
\hline Id & Attribute & Cat & Type & Min...max & Meaning \\
\hline 1 & curricular_year_s & $\mathrm{C}$ & Discrete & $1 . .4$ & Student's course year in the a.s. considered \\
\hline 2 & academic_year_s & $\mathrm{C}$ & Discrete & $07 . .15$ & Academic year of the a.s. considered \\
\hline 3 & scholarship_s & $\mathrm{C}$ & Continuous & $0 . .1$ & Was the student a scholarship holder in the a.s.? \\
\hline 4 & union_member_s & $\mathrm{C}$ & Continuous & $0 . .1$ & Was the student a union leader in the a.s.? \\
\hline 5 & ects_aprov_s & $\mathrm{C}$ & Discrete & $0 . .60$ & N. of ECTS passed in the a.s. \\
\hline 6 & ects_disaprov_s & $\mathrm{C}$ & Discrete & $0 . .60$ & N. of ECTS failed in the a.s. (academic semester) \\
\hline 7 & max_s & $\mathrm{C}$ & Discrete & $0 . .20$ & Maximum mark of the CUs passed in the a.s. \\
\hline 8 & average_s & $\mathrm{C}$ & Continuous & $0 . .20$ & Average mark of the CUs passed in the a.s. \\
\hline 9 & min_s & $\mathrm{C}$ & Discrete & $0 . .20$ & Minimum mark of the CUs passed in the a.s. \\
\hline 10 & n_assess_disap_s & $\mathrm{C}$ & Discrete & $0 . .18$ & N. of assessments failed in the a.s. \\
\hline 11 & n_courses_aprov_s & $\mathrm{C}$ & Discrete & $0 . .10$ & N. de CUs passed in the academic semester \\
\hline 12 & n_courses_disap_s & $\mathrm{C}$ & Discrete & $0 . .10$ & N. of CUs failed in the academic semester \\
\hline 13 & $\mathrm{dv} 12 \_\mathrm{s}^{(\mathrm{a})}$ & $\mathrm{C}$ & Continuous & $-20 . .20$ & Diff. in performance from 1 st to 2 nd semester \\
\hline 14 & dv23_s (a) & $\mathrm{C}$ & Continuous & $-20 . .20$ & Diff. in performance from 2 nd to 3 rd semester \\
\hline 15 & dv34_s (a) & $\mathrm{C}$ & Continuous & $-20 . .20$ & Diff. in performance from 3 rd to 4 th semester \\
\hline 16 & $\mathrm{dv} 45 \_\mathrm{s}^{(\mathrm{a})}$ & $\mathrm{C}$ & Continuous & $-20 . .20$ & Diff. in performance from 4 th to 5 th semester \\
\hline 17 & dv56_s $(a)$ & $\mathrm{C}$ & Continuous & $-20 . .20$ & Diff. in performance from 5 th to 6 th semester \\
\hline 18 & enrol_year & M & Discrete & $07 . .13$ & Year of enrolment \\
\hline 19 & cod_degree & M & Nominal & $1 . .51$ & Code of the degree course \\
\hline 20 & cod_school & M & Nominal & $1 . .5$ & Code of the school \\
\hline 21 & cred_ects_tx & M & Discrete & $0 . .100$ & Fraction of ECTS credited to the student \\
\hline 22 & ects_degree & M & Discrete & $180 . .240$ & Number of ECTS of the degree course \\
\hline 23 & enrol_type & $\mathrm{M}$ & Nominal & $1 . .9$ & Type of enrolment in the degree course \\
\hline 24 & displaced & $\mathrm{D}$ & Binary & $0 . .1$ & Is the student displaced from usual residence? \\
\hline 25 & district & $\mathrm{D}$ & Nominal & $1 . .28$ & Student's district of origin \\
\hline 26 & district_n & $\mathrm{D}$ & Nominal & $1 . .27$ & District of birth \\
\hline 27 & age & $\mathrm{D}$ & Discrete & $17 . .61$ & Student's age at the time of enrolment \\
\hline 28 & nationality & $\mathrm{D}$ & Nominal & $1 . .15$ & Student's nationality \\
\hline 29 & gender & $\mathrm{D}$ & Nominal & $1 . .2$ & Gender \\
\hline 30 & cod_job_student & $\mathrm{S}$ & Nominal & $1 . .12$ & Student's job \\
\hline 31 & cod_job_mother & $\mathrm{S}$ & Nominal & $1 . .12$ & Mother's job \\
\hline 32 & cod_job_father & $\mathrm{S}$ & Nominal & $1 . .12$ & Father's job \\
\hline 33 & educ_level_mother & S & Ordinal & $1 . .13$ & Mother's level of education \\
\hline 34 & educ_level_father & $\mathrm{S}$ & Ordinal & $1 . .13$ & Father's level of education \\
\hline 35 & prof_sit_student & $\mathrm{S}$ & Nominal & $1 . .10$ & Student's employment status \\
\hline 36 & prof_sit_mother & S & Nominal & $1 . .10$ & Mother's employment status \\
\hline 37 & prof_sit_father & $\mathrm{S}$ & Nominal & $1 . .9$ & Father's employment status \\
\hline 38 & phase & A & Ordinal & $1 . .3$ & Phase of enrolment \\
\hline 39 & access_grade & A & Continuous & $0 . .200$ & Student's entrance qualification \\
\hline 40 & a10_11_grade & A & Continuous & $0 . .200$ & Mean obtained in the 10 th and 11 th grades \\
\hline 41 & a12_grade & A & Continuous & $0 . .200$ & Mean obtained in the 12 th grade \\
\hline 42 & access_option & A & Ordinal & $1 . .6$ & Order of the option when applying for university \\
\hline 43 & access_order & A & Discrete & $1 . .322$ & Order of entrance among stud. admit. in course \\
\hline 44 & access_exams & A & Continuous & $0 . .200$ & Mean obtained in the entrance examinations \\
\hline 45 & $\mathrm{dv}^{(\mathrm{b})}$ & & Continuous & $0 . .20$ & Dependent var. with student's final performance \\
\hline
\end{tabular}


curricular data (C) refers to semestral curricular results of academic performance accumulated at the end of each of the student's 6 first semesters.

The selection of the dimensions regarding the student, which explain their academic success, was carried out in two different stages. First, as explained in Sect.4.1, we selected the student's dimensions which best account for their success, which allowed a first adjustment enabling the exclusion of complete groups of variables. Subsequently, as explained in Sect.4.2, we fine-tuned the selection of attributes which were not excluded in the first stage. This approach allowed the reduction of the data dimensionality without losing the model's predictive capacity.

Figure 1 depicts a scheme intended to characterise the predictive model designed for this study. It shows the different categories of predictive variables used as input of the random forest algorithm. As we can see, for the group of curricular variables $(\mathrm{C})$, the attributes used are the results accumulated at the end of each one of the student's 6 first semesters. Note that only one of the 6 entries of curricular data (C) is considered in each execution of the algorithm (mutually exclusive entries).

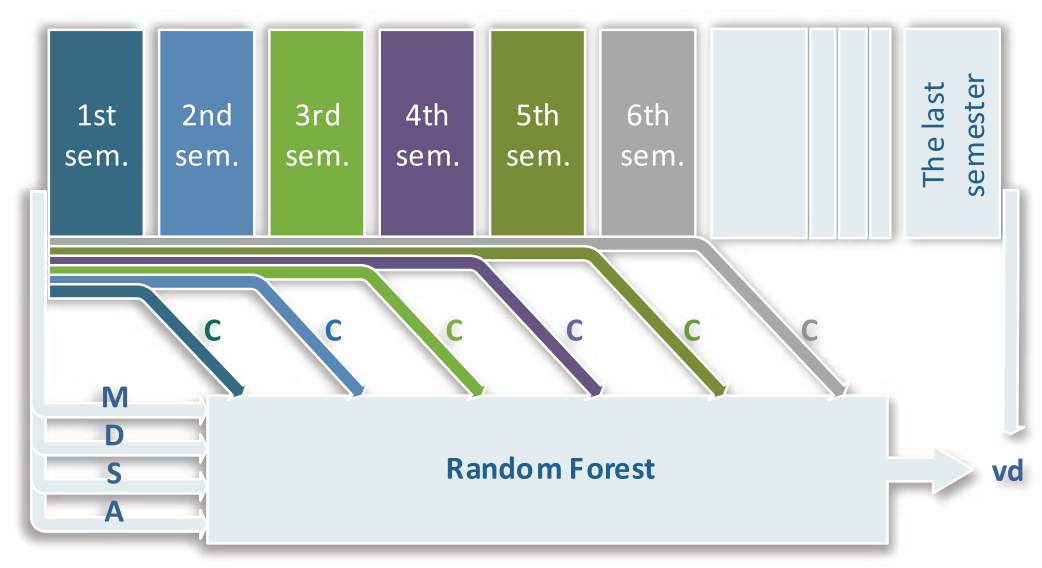

Fig. 1. Scheme depicting the comparative study conducted.

\section{Results}

In the exploratory analysis of data which follows, we chose to keep the configuration of the random forest algorithm fixed for the study to focus on the set of predictive variables which sustain it.

\subsection{Selection of Predictors Categories}

As it is known, the assertiveness of a predictive model depends greatly on the set of predictive variables being considered in the analysis. Also, the best model is not always the one which includes all the variables available. Although it 
is commonly acknowledged that random forests make an internal selection of variables, we still decided to run a test of inclusion, or not, of the categories of variables so as to understand the impact of the several dimensions on the capacity of the model.

Table 2 shows the different categories of attributes chosen in each of those studies. Although the aim is to develop a comprehensive study, it does not seem necessary to include all the possible combinations between the 5 groups of variables, which makes a total of $2^{5}-1=31$ possibilities. In fact, since the group of curricular data $(\mathrm{C})$ is clearly the most determinant group of predictors, great difficulties are foreseen in the predictive precision of any model which does not include it. Therefore, only one particular case is considered in which this group of variables is not used: case MDSA (Study 6). With this simplification, the number of studies was reduced to almost a half, or more precisely to $2^{4}+1=17$.

Table 2. Categories of predictive variables used in the studies conducted.

\begin{tabular}{|c|c|c|c|c|c|c|}
\hline Study & Label & Curricular & Matriculation & Demographic & Socioeconomic & Access \\
\hline 1 & CMDSA & $\checkmark$ & $\checkmark$ & $\checkmark$ & $\checkmark$ & $\checkmark$ \\
\hline 2 & CMDS & $\checkmark$ & $\checkmark$ & $\checkmark$ & $\checkmark$ & \\
\hline 3 & CMDA & $\checkmark$ & $\checkmark$ & $\checkmark$ & & $\checkmark$ \\
\hline 4 & CMSA & $\checkmark$ & $\checkmark$ & & $\checkmark$ & $\checkmark$ \\
\hline 5 & CDSA & $\checkmark$ & & $\checkmark$ & $\checkmark$ & $\checkmark$ \\
\hline 6 & MDSA & & $\checkmark$ & $\checkmark$ & $\checkmark$ & $\checkmark$ \\
\hline 7 & CMD & $\checkmark$ & $\checkmark$ & $\checkmark$ & & \\
\hline 8 & CMS & $\checkmark$ & $\checkmark$ & & $\checkmark$ & \\
\hline 9 & CMA & $\checkmark$ & $\checkmark$ & & & $\checkmark$ \\
\hline 10 & CDS & $\checkmark$ & & $\checkmark$ & $\checkmark$ & \\
\hline 11 & CDA & $\checkmark$ & & $\checkmark$ & & $\checkmark$ \\
\hline 12 & CSA & $\checkmark$ & & & $\checkmark$ & $\checkmark$ \\
\hline 13 & $\mathrm{CM}$ & $\checkmark$ & $\checkmark$ & & & \\
\hline 14 & CD & $\checkmark$ & & $\checkmark$ & & \\
\hline 15 & CS & $\checkmark$ & & & $\checkmark$ & \\
\hline 16 & $\mathrm{CA}$ & $\checkmark$ & & & & $\checkmark$ \\
\hline 17 & $\mathrm{C}$ & $\checkmark$ & & & & \\
\hline
\end{tabular}

Table 3 contains for each of the studies the determination coefficients $\left(\mathrm{R}^{2}\right)$ obtained by applying the random forest predictive algorithm to the selected data at the end of the student's 6 first academic semesters. For a better understanding of the results presented, take Study 8 as an example: the input of the random forest algorithm (see Fig. 1) was reduced to the groups of curricular (C), matriculation (M) and socioeconomic (S) variables. In this study, as in all the others (except for Study 6, which does not include the curricular data), the random forest algorithm was run 6 times in order to use the results accumulated at the end of each of the 6 semesters concerning the curricular data. The last column of the table shows the weighted average of the determination coefficients for those 
Table 3. Determination coefficient $\mathrm{R}^{2}$ of the predictive model, for different groups of predictive variables according to students' academic semester.

\begin{tabular}{|c|c|c|c|c|c|c|c|c|}
\hline & Label & 1st sem & 2nd sem & 3rd sem & 4 th sem & 5 th sem & 6th sem & Average ${ }^{(a)}$ \\
\hline Study 13 & $\mathrm{CM}$ & 80.4 & 86.5 & 92.0 & 94.3 & 96.6 & 97.9 & 88.4 \\
\hline Study 8 & CMS & 80.7 & 86.8 & 91.7 & 93.9 & 96.4 & 97.7 & 88.4 \\
\hline Study 4 & CMSA & 80.7 & 86.5 & 91.6 & 93.9 & 96.3 & 97.7 & 88.3 \\
\hline Study 1 & CMDSA & 80.3 & 86.3 & 91.3 & 93.7 & 96.2 & 97.6 & 88.1 \\
\hline Study 2 & CMDS & 80.3 & 86.4 & 91.4 & 93.7 & 96.3 & 97.7 & 88.1 \\
\hline Study 7 & CMD & 79.8 & 86.3 & 91.6 & 94.0 & 96.5 & 97.8 & 88.1 \\
\hline Study 9 & CMA & 79.9 & 86.2 & 91.6 & 94.0 & 96.4 & 97.7 & 88.1 \\
\hline Study 3 & CMDA & 79.7 & 86.1 & 91.4 & 93.8 & 96.3 & 97.7 & 87.9 \\
\hline Study 12 & CSA & 70.5 & 78.8 & 86.6 & 89.9 & 94.2 & 96.6 & 81.8 \\
\hline Study 15 & CS & 70.6 & 78.7 & 86.5 & 89.7 & 94.1 & 96.5 & 81.8 \\
\hline Study 5 & CDSA & 70.5 & 78.5 & 86.4 & 89.8 & 94.2 & 96.5 & 81.7 \\
\hline Study 10 & CDS & 70.7 & 78.3 & 86.2 & 89.6 & 94.1 & 96.4 & 81.6 \\
\hline Study 17 & C & 70.3 & 78.0 & 86.6 & 90.0 & 94.4 & 96.7 & 81.6 \\
\hline Study 16 & $\mathrm{CA}$ & 69.6 & 78.2 & 86.6 & 90.1 & 94.4 & 96.7 & 81.5 \\
\hline Study 11 & $\mathrm{CDA}$ & 69.8 & 78.2 & 86.3 & 89.9 & 94.3 & 96.6 & 81.4 \\
\hline Study 14 & CD & 70.1 & 77.8 & 86.3 & 89.6 & 94.2 & 96.6 & 81.4 \\
\hline Study 6 & MDSA & 64.4 & 64.4 & 64.4 & 64.4 & 64.4 & 64.4 & 64.4 \\
\hline Average $^{(b)}$ & & 75.2 & 82.4 & 89.0 & 91.9 & 95.3 & 97.2 & 84.9 \\
\hline
\end{tabular}

6 semesters. The choice fell on a weighted average of semestral $\mathrm{R}^{2}$ in order to value the results of the first semesters at the expense of those obtained in more advanced stages of the student's academic path - note, for example, that for students who complete their training in 3 years, the predictive capacity of the model after the 6th semester is totally irrelevant.

The analysis of the values presented in the table, listed in a descending order of the average value of $\mathrm{R}^{2}$ (last column), allows the following considerations:

- It was not the model 'feeding' on all the variables (Study 1 - CMDSA) which presented the best predictive capacities. Actually, 6 other models achieved similar or better performances with a lower number of predictive variables.

- There is a visibly big difference in the performance of the 8 best classified models and the remaining ones - note the sudden drop between Study 3 and Study 12. If that sudden drop is clearly due to the loss of the matriculation data (M), while the one witnessed between studies 14 and 6 is due to the loss of the other subgroup of academic data, the curricular data (C).

- Academic data (subgroups CM, Study 13), alone, justify the best study result $\left(\mathrm{R}^{2}=88.4 \%\right)$, obtained in ex-aequo with Study 8 (CMS).

- As expected, the assertiveness of the model increases consistently in line with the course of students' academic path.

- Although the results of Study 6 (MDSA), the only one not using the attributes of category $\mathrm{C}$, are far behind the others, they clearly confirm that students' 
curricular data is the key contributor to the assertive capacity of the model, probably not least because such data is not available at the beginning of the academic path. Still, it is interesting to observe that even at a very early stage of students' academic course, namely in the 1st and 2nd semesters, the average determination coefficient of the model showing the best performance skyrockets from $64.4 \%$ to values greater than $80 \%$ and $86 \%$, respectively.

In light of the results presented in Table 3 and of the corresponding considerations exposed, it seems pertinent to propose the groups of variables in Study 13 (categories $\mathrm{CM}$ ) for the predictive model we intend to design. The study achieves the highest determination coefficients using only 2 of the 5 possible categories of variables. Supporting the choice of the group CM (Study 13) as the best study is also the fact that this set of variables also revealed, in additional tests, the lowest Root Mean Square Error (0.966 when the second lowest error was 0.983 and the average 1.105).

The comparative study conducted allowed the exclusion of three irrelevant groups of variables, from a predictive perspective: the demographic, socioeconomic and the access data. In the next stage, we will try to exclude variables presenting a negligible influence in the performance of the predictive model.

\subsection{Additional Adjustment of the Model - Selection of Predictors}

The performance of any predictive model to be proposed will be all the more valued as the earlier the moment in which it might be applied. In fact, the predictive relevance of a model is based on two crucial aspects: the veracity of its predictions and the degree of anticipation of such predictions. Therefore, it is now important to fine-tune the CM model (which globally showed to be the most assertive) when applied right at the end of the student's 1st semester, as shown in the scheme in Fig. 2. More precisely, we will try to exclude from the set of CM predictive variables (with the subgroup $\mathrm{C}$ including only the curricular results of the student's 1st semester) all those which do not contribute positively and significantly to the quality of the model.

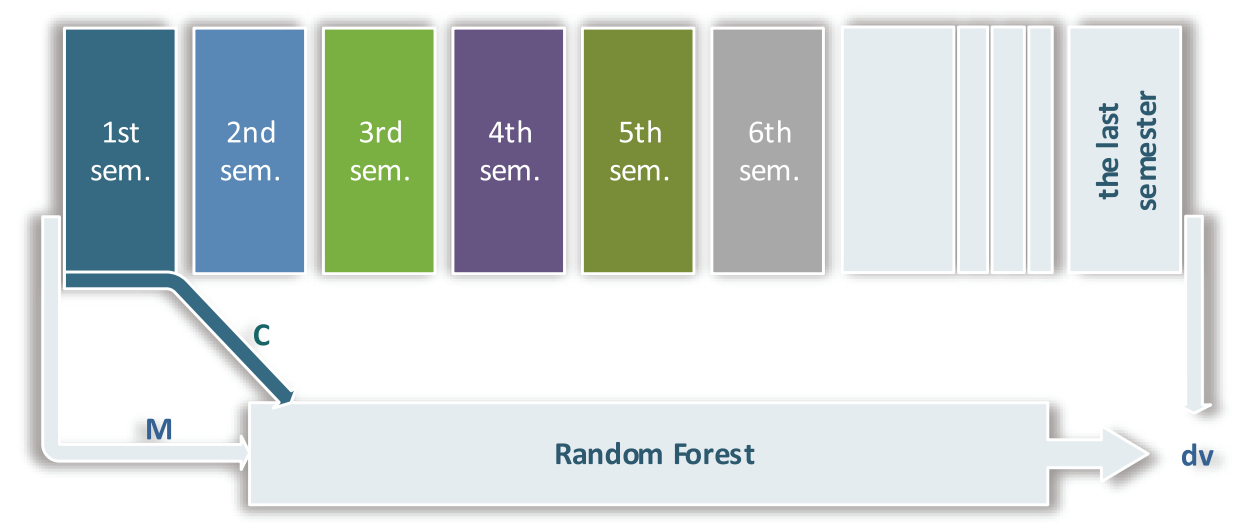

Fig. 2. CM predictive model sustained by data from the 1st academic semester. 
Since the CM model did not make use of the socioeconomic and access data, the categories with missing data in a significant number of students, it was possible to use a wider and more comprehensive sample of matriculations containing complete data. Therefore, the size of the data set according to which the CM model will be adjusted increased from 2159 to 4530, the total size of the sample, originating a slight decrease of the model assertiveness in the 1st semester, from $\mathrm{R}^{2}=80.4$ to 79.0 . We believe that by using a larger sample of matriculations in this second adjustment of the model, it will present greater generalization capacity.

Before moving on to a more systematised process of fine-tuning of the CM model, the random forest algorithm was run for the data set without variables $\mathrm{n}_{-}$courses_aprov_s and $\mathrm{n}_{-}$courses_disap_s, for considering them to have a strong correlation with the attributes ects_aprov_s and ects_disaprov_s, respectively. After confirming the pertinence of excluding these two attributes, the possibility to exclude new variables among those revealing to be less informative, based on random forest ranking of variables in terms of importance, was assessed in successive iterations. The relevant data characterising those several iterations is summarised in Table 4. The data shows that the loss of variables maintained or slightly improved the assertiveness of the model. In a nutshell, we were able to remove 7 out of the 18 attributes from the data set without that affecting negatively the model performance and actually achieving a slight improvement, though of little significance.

Table 4. Removal of variables from the CM data set.

\begin{tabular}{l|l|l|l|l|l}
\hline Iter. & Excluded variables & \#var & $\mathrm{R}^{2}$ & $\mathrm{RMSE}$ \\
\hline 0 & n_courses_aprov_s & n_courses_disap_s & 16 & 79.2 & 1.334 \\
\hline 1 & scholarship_s & union_member_s & 14 & 79.2 & 1.335 \\
\hline 2 & min_s & & 13 & 79.2 & 1.333 \\
\hline 3 & max_s & & 12 & 79.3 & 1.329 \\
\hline 4 & n_assess_disap_s & & 11 & 79.5 & 1.326 \\
\hline
\end{tabular}

The 11 variables, which together justify the predictive capacity of the model and therefore reveal to be the most determinant in anticipating the academic success of IPB's bachelor degree students were ordered in a descending order of importance (given in brackets) as follows: ects_disaprov_s (2.387), cod_degree (2.011), average_s (1.785), ects_aprov_s (1.461), cred_ects_tx (1.454), cod_school (1.230), ects_degree (0.359), enrol_type (0.274), academic_year_s (0.241), enrol_year (0.239), curricular_year_s (0.176).

\section{Discussion of Results and Conclusions}

In this study, the random forest method was used to propose a predictive model of the global academic success of IPB's bachelor degree students at the terminus 
of their academic path. Instead of following the commonly adopted procedure of delimiting the prediction to one single specific course, the model was developed from a vast real data set involving records of quite heterogeneous undergraduates from over half a hundred degree courses covering a wide variety of educational fields taught in the five schools composing the institution and where each student is characterized by more than four tens explanatory variables. Such specificity allowed studying the influence of a new curricular factor taken into account for the first time in literature: the type of school. The results obtained allowed concluding that students' success also depends on the school they attend. This conclusion indicates that in order to mitigate retention and academic failure, it might be necessary to adopt differentiated strategies of educational promotion according to each school.

The order of importance provided by the random forest algorithm allowed the identification of the factors contributing to students' success or failure. It enabled the observation that the factors regarding the curricular context of students' academic performance are paramount to the intended prediction, which confirms results previously obtained by [15], who stated that such factors can alone account for academic performance. Note that all 11 attributes which revealed to be significant for the prediction belong, without exception, to the curricular or matriculation categories.

The knowledge obtained allows the identification of students at a higher risk of retention and academic failure, which enables the institutional managers to design more assertive educational or tutorial strategies towards educational efficacy and efficiency.

The kind of approach adopted in the identification of students' characteristics which best account for their success seems to differ from that usually used in works related to the same topic. In the present work, the selection of those characteristics was conducted in two different stages. First, the selection of students' dimensions which best explain their success allowed a first adjustment of the model by eliminating complete groups of variables. Later, a fine-tuned adjustment led to the selection of the attributes which were not excluded in the first stage. This approach enabled us, in addition to reduce the 'plague' of the data dimensionality at an early stage, to exclude completely categories of variables, without losing the predictive capacity of the model. This feature is of particular importance since it contributes to the reduction of the multidisciplinarity of the predictors, thereby lowering some of the complexity of the predictive process, and, more importantly, makes it possible to extend the study to other contexts, where not all categories of variables initially considered in this study are available.

Note however, that a significant part of the results obtained in this study cannot be generalized to the whole context of higher education since they were based on a data sample non-representative of that broader context. This study presented a case study focused on IPB, which for being an institution of the polytechnic higher education subsystem and for being located in an inland region with low population density cannot reach the same heterogeneity of students 
as other institutions located in large coastal urban centres. At best, the results presented here may reflect the reality of higher education institutions with similar conditions to those of the IPB such as other polytechnic institutes located in inland regions of the country far from the big urban centres.

Acknowledgments. This work was supported by the Portuguese Foundation for Science and Technology (FCT) under Project UID/EEA/04131/2013. The authors would also like to thank the Polytechnic Institute of Bragança for making available the data analysed in this study.

\section{References}

1. Breiman, L.: Random forests. Mach. Learn. 45(1), 5-32 (2001)

2. Romero, C., Ventura, S.: Educational data mining: a survey from 1995 to 2005. Expert Syst. Appl. 33(1), 135-146 (2007)

3. Romero, C., Ventura, S.: Educational data mining: a review of the state of the art. IEEE Trans. Syst. Man Cybern. Part C (Appl. Rev.) 40(6), 601-618 (2010)

4. Romero, C., Ventura, S.: Data mining in education. Wiley Interdisc. Rev.: Data Min. Knowl. Disc. 3(1), 12-27 (2013)

5. Baker, R.S.J.D., Yacef, K.: The state of educational data mining in 2009: a review and future visions. JEDM-J. Educ. Data Min. 1(1), 3-17 (2009)

6. Huebner, R.A.: A survey of educational data-mining research. Res. Higher Educ. J. 19, 1-13 (2013)

7. Papamitsiou, Z.K., Economides, A.A.: Learning analytics and educational data mining in practice: a systematic literature review of empirical evidence. Educ. Technol. Soc. 17(4), 49-64 (2014)

8. Peña-Ayala, A.: Educational data mining: a survey and a data mining-based analysis of recent works. Expert Syst. Appl. 41(4), 1432-1462 (2014)

9. Algarni, A.: Data mining in education. Int. J. Adv. Comput. Sci. Appl. 7, 456-461 (2016)

10. Shahiri, A.M., Husain, W., Rashid, N.A.: A review on predicting student's performance using data mining techniques. Procedia Comput. Sci. 72, 414-422 (2015)

11. Del Río, C.A., Insuasti, J.A.P.: Predicting academic performance in traditional environments at higher-education institutions using data mining: a review. Ecos de la Academia. 2016(7), 185-201 (2016)

12. Natek, S., Zwilling, M.: Student data mining solution-knowledge management system related to higher education institutions. Expert Syst. Appl. 41(14), 6400-6407 (2014)

13. Asif, R., Merceron, A., Ali, S.A., Haider, N.G.: Analyzing undergraduate students' performance using educational data mining. Comput. Educ. 113, 177-194 (2017)

14. Miguéis, V.L., Freitas, A., Garcia, P.J.V., Silva, A.: Early segmentation of students according to their academic performance: a predictive modelling approach. Decis. Support Syst. 115, 36-51 (2018)

15. Manhães, L.M.B.: Predição Do Desempenho Acadêmico De Graduandos Utilizando Mineração De Dados Educacionais. Ph.D. thesis (Tese Doutorado), Universidade Federal do Rio de Janeiro (2015) 